\title{
Seventy five years of arthritis research at the Strangeways Research Laboratory: 1912-87
}

\author{
J T DINGLE
}

To all to whom these presents shall come, Sir William Selby Church, Baronet, Sir Thomas Clifford Allbutt. Regius Professor of Physic for Cambridge University, Germaine Sims Woodhead, Professor of Pathology for Cambridge University and Thomas Strangeways Pigg-Strangeways. Whereas these have formed themselves into a committee for the study of special diseases and for the systematic investigation of the more important diseases, the pathology and treatment of which are at present undetermined, have opened a fund for the furtherance of the above objects. Now these persons witness and it is hereby declared that the said Thomas Strangeways Pigg-Strangeways will stand possessed of the same piece of land so purchased and that a research hospital and laboratories and buildings be erected thereon ....

DEED POLL, 16 November 1912

Such was the beginning of the Cambridge Research Hospital, which later developed into the Strangeways Research Laboratory. Dr Strangeways, the Huddersfield lecturer in pathology in the University of Cambridge, had long had an interest in arthritic diseases but was well aware that little scientific or clinical research was being carried out at that time. He became determined to found a research hospital to initiate such investigations, and the hospital was started in 1905 in a house in Hartington Grove, Cambridge. In 1912 the hospital moved to the present building in Worts Causeway in which there were small wards for patients and accommodation for the nursing staff. In 1923 Strangeways decided that clinical investigations would be best carried out in a larger hospital with more beds, and the clinical work was transferred to St Bartholomew's Hospital in London. Dr Strangeways continued to be advisor on the treatment of patients, and by the time of his death in 1926 over 4000 sufferers from arthritis had received help.

Dr Strangeways had come to the conclusion that a more fundamental approach was needed to study the basis of arthritic disease, and after the closure of the wards the rooms were turned into research laboratories. Strangeways was well ahead of his time in deciding to investigate the possibility of cell and organ culture techniques. In 1923 he was joined by a young research assistant from Edinburgh, one
Honor Bridget Fell, and they worked together until Strangeways' death.

On Strangeways' death the research hospital faced extinction. He had, to quote $F$ G Spear (History of The Strangeways Research Laboratory, 1912-1962), 'imagined, created, funded and governed it', and the full extent of his unstinted generosity from his professional earnings can be traced in its books. There is little doubt that his family suffered financially by the extent to which he supported the Laboratory. The Hospital, which was built in a domestic style so that it could be sold as a residence, had at this stage only four of the rooms in use, and only one member of the small staff was over 30. The trustees had long and agonising discussions before it was decided to continue the Laboratory; this was due in the main to the Medical Research Council who played a vital role in the finance. The governors' most important decision was to appoint Honor Fell as director. During the subsequent years up to the second world war a number of bequests enabled the laboratory to keep going and to expand, but never during this period was the Laboratory entirely sure of its future.

During the second world war the Laboratory was mainly concerned with government service, and research at the basic level had to be put on one side. After the war Honor Fell was able to obtain finance from the Royal Society, from the Rockefeller Foundation, and in particular from the Nuffield Foundation, which enabled the slow expansion of the Laboratory to begin. The original aim of Dr Strangeways to investigate the basic processes of arthritic disease was extended to cover a wider interest in cell biology, with a particular interest in developmental biology. Under the guidance of Honor Fell the Laboratory achieved a world wide reputation for skill in cell, tissue, and organ culture. In addition, the staff continued to apply the radiological and time lapse ciné-microphotography techniques which had been developed by Strangeways and his colleagues (notably Canti) in the 1920s, and a new dimension was added to the Laboratory's research in 1950 with the introduction of ultrastructural studies by Audrey Glauert. Honor Fell encouraged collaborative studies between colleagues in different 


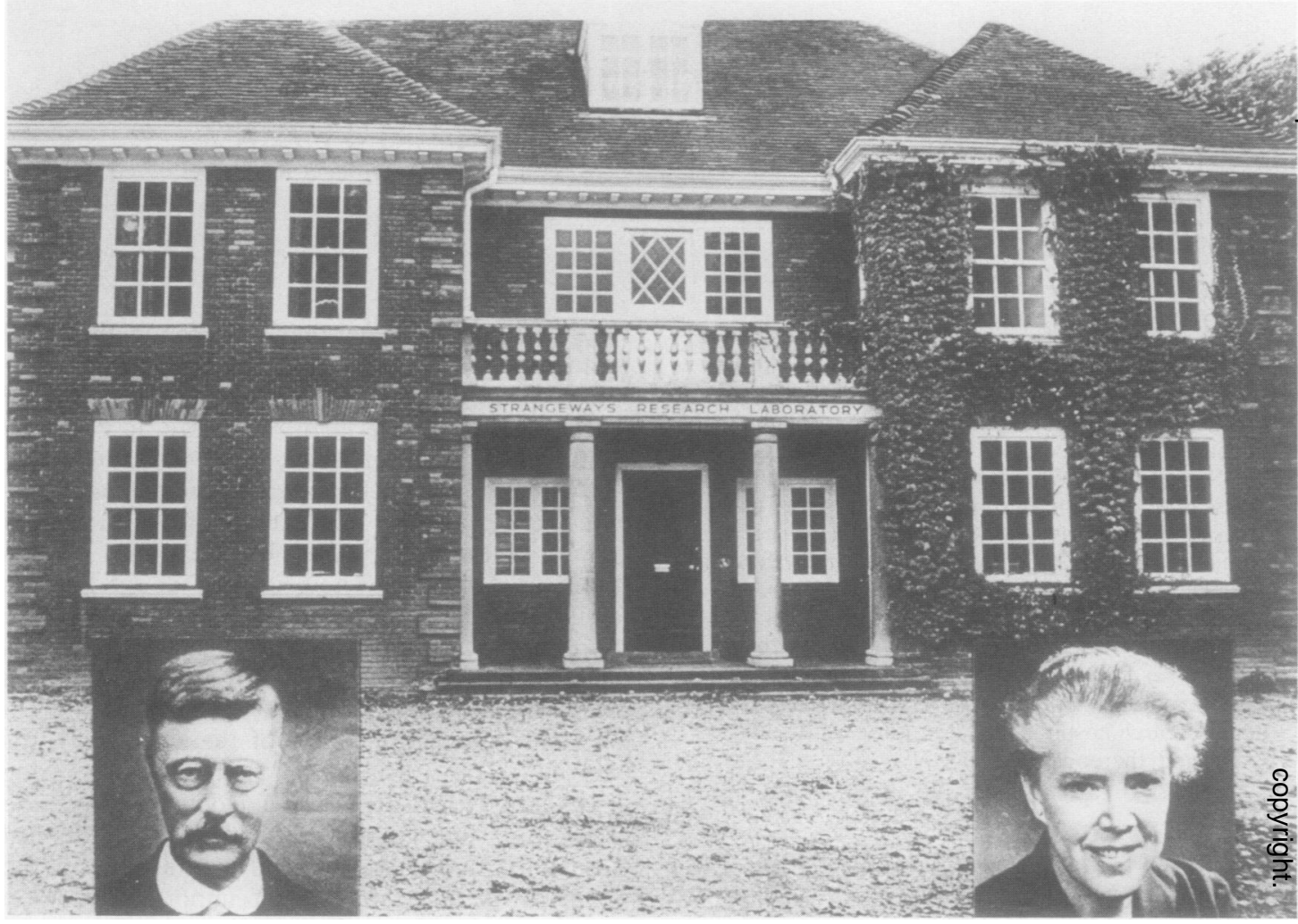

Fig. 1 Strangeways Research Laboratory. Inset: Dr. Strangeways and Dame Honor Fell.

disciplines, and there was an increasing involvement of biochemical investigations in all projects at the Laboratory during her directorship. Michael Abercrombie had much the same aims in research, and it was therefore appropriate that he should take over as director of the Laboratory on the retirement of Dame Honor Fell (as she now was) in 1970). Abercrombie and his group developed the technique of time lapse ciné-microphotography into a powerful tool for the analysis of cell movement, thus carrying on the tradition established by Canti in the early days of the Laboratory. After Abercrombie's untimely death in 1979 this work was transferred to King's College. London. and I took over as director.

In parallel with the work in cell biology the Laboratory continued to be interested in human disease, but the emphasis during the $40 \mathrm{~s}$ and $50 \mathrm{~s}$ was in the cancer field. where the work of Alfred Glucksmann and Ilse Lasnitzki was highly regarded.

By the early 1960)s the direction of the Laboratory's research had gradually begun to change back towards arthritis. I joined the Laboratory in 1959 as research assistant to Honor Fell. having spent some
10 vears in the Roval National Hospital for Rheumatic Diseases in Bath (incidentally in 190) the hospital was one of the earliest collaborator? with Dr Strangeways). and was able to give impetuso to the change in direction of the research. During this period we gradually developed work on the catabolic reactions of connective tissues with speciah reference to arthritic disease. The strengthening of the rheumatology department at Addenbrookes Hospital with the advent of Dr Brian Hazleman lecB to a close association and has greatly assisted our work on clinical material. During recent years we. have established departments of molecular enzymolNo ogy, cell biology, and tissue physiology, enabling work to be done at the molecular, cellular, tissue animal. and patient levels in understanding thew mechanisms involved in the destructive processes of catabolic diseases. Our special interests, which steno from the work in the 30 s by Honor Fell on the development of the chick limb rudiment, have been ${ }^{\text {? }}$ in the connective tissues of the joint and in particular in the synovial/cartilage interaction. Mos? recently the discovery of local mediators that controß 
the dynamic equilibrium between synthesis and degradation in cartilage, bone, and other connective tissues has added great impetus to our research in this area. A worldwide interest in the control of such catabolic mechanisms has developed, which I am sure would have been very gratifying to $\mathrm{Dr}$ Strangeways.

The financing of the Strangeways Laboratory has always been a major problem since its inception. Strangeways was not a rich man and was not able to provide any endowment. We have achieved our scientific research reputation entirely upon funds provided by the Medical Research Council and various charities. In most recent years the most prominent of the charities has been the Arthritis and Rheumatism Council, which has provided many project grants and has helped to stimulate the fundamental research on joint destruction in many different ways. We have also been fortunate that private individuals and small foundations such as the Sybil Eastwood Fund have enabled us to prime the pump' and make new initiatives which have developed into major areas of research. Nevertheless. the major support of the Laboratory continues to be the Medical Research Council, and we hope that the financial situation affecting all research in this country will not preclude this happy relationship from continuing.

In conclusion, the Strangeways' Laboratory staff of about 60 scientists and 40 supporting staff continue to be a major research force in the area of connective tissue catabolism and in particular in studies on the control of arthritic damage. The present day aims of the laboratory are compatible with Strangeways' original initiative. It is to be hoped that there is still scope for an independent research institute of this type for the next 75 years. 